\title{
Association between Abdominal Wall Fat Index (AFI) on Ultrasonography with Carotid Intima Media Thickness (CIMT) and Lipid Profile
}

\author{
JOSEPH K. HALIM, M.Sc.; AHMED M. MONIB, M.D. and MARWA ELSAYED ABDELRAHMAN, M.D. \\ The Department of Radiology, Faculty of Medicine, A in Shams University
}

\begin{abstract}
Background: Many international organizations have recognized obesity as a chronic disease, with significant contribution to the global mortality and morbidity. Besides, obese patients are at higher risk of death than non-obese individuals. Obesity is a major driver for disability, early retirement, and psychological disorders as well.
\end{abstract}

Abdominal wall fat index (AFI) is a widely utilized sonographic measure for regional fat accumulation; it is calculated as a ratio of the highest to lowest preperitoneal and subcutaneous fat thicknesses, respectively. Carotid Intima Media Thickness (CIMT) is a well-established marker for early atherosclerosis.

In this study we investigated the relationship between abdominal wall fat index (AFI) and Carotid Intima Thickness (CIMT) with lipid profile among overweight and obese patients.

Aim of Study: Investigating the relationship between abdominal wall fat index (AFI) and Carotid Intima Media Thickness (CIMT) as measured by ultrasonography with lipid profile among overweight and obese patients.

Patients and Methods: We conducted a cross-sectional study on 60 adult participants ranging from 22 to 66 years old of both genders. The patients were divided into three groups according to the AFI value into: Group I (AFI <0.7), group II (AFI <1.4), and group III (AFI $\geq 1.4)$. AFI and CIMT measured using ultrasonography and lipid profile was obtained.

Results: Participants in group III (mean $=53.7 \pm 11.0$ years old) were significantly older than other studied groups; and were more likely to be hypertensive and diabetic. There was a statistically significant difference between studied groups regarding body mass index (BMI; $p=0.001)$, the highest level was among group III (mean BMI $=34.1 \pm 5.8 \mathrm{Kg} / \mathrm{m}^{2}$ ). There were positive correlations between lipid profile parameters and the AFI. Furthermore, there was a statistically significant difference between groups regarding CIMT $(p=0.001)$. CIMT was the highest among group III (mean of $1.4 \pm 0.3 \mathrm{~mm}$ ) followed by group II (mean of $1.2 \pm 0.3 \mathrm{~mm}$ ), and group I (mean

Correspondence to: Dr. Joseph K. Halim, The Department of Radiology, Faculty of Medicine, Ain Shams University of $0.7 \pm 0.3 \mathrm{~mm}$ ).CIMT was positively correlated with AFI $(r=0.747, p=0.001$ ). BMI was highest among group III (mean of $34.1 \pm 5.8$ ), followed by group II (mean of $30.3 \pm 4.0$ ), and group I (mean of $25.0 \pm 2.2$ ) BMI was positively correlated with AFI $(p=0.001)$.

Conclusions: AFI has a significant positive correlation with CIMT and preperitoneal fat thickness. AFI can be a useful marker in evaluating and predicting disorders of metabolism, circulation and atherosclerosis.

Key Words: Abdominal wall fat index-Carotid intima media thickness - Obesity.

\section{Introduction}

BY the end of the first decade of 2000s, many international organizations have recognized obesity as a chronic disease, with significant contribution to the global mortality and morbidity [1]. The global epidemiology of obesity has witnessed dramatic increase in the past few decades to the extent of reaching a pandemic levels and being declared as "the single greatest threat to public health for this century" [2]; the recent international figures demonstrated that the prevalence of obesity has reached $10.8 \%$ and $14.9 \%$ of the global male and female adult population, respectively [3] . The steady increase in the prevalence of obesity was observed even among developing and low-income countries, with the highest incremental increase observed in Eastern Europe, Latin America, and Middle East [4] . According to World Health Organization (WHO) estimations, nearly 1.9 billion of the adult global population are overweight and 650 million are obese [5] . Obesogenic lifestyle behaviors (such as excessive junk foods, excessive sweets, limited physical activities, and sedentary habits) combined with genetic susceptibility are widely thought to be the major contributor to the current obesity pandemic [6]. The pathogenesis of obesity is mul- 
tifactorial and involve imbalance in caloric intake/ consumption, dysregulation in hormonal status (such as excessive release of adipokines and gut hormones), and chronic inflammatory process leading to proinflammatory cytokines such as interleukin-6 (IL-6) and tumour-necrosis factor alpha (TNF-(x) [4]. In return, such factors lead to excessive deposition of visceral fat, which is the hallmark for obesity [7]. The cumulative body of evidence shows that obesity is an independent risk factors for wide range of metabolic and nonmetabolic disorders, including impaired glycaemic control and diabetes, hypertension, cardiovascular disease, non-alcoholic fatty liver, osteoarthritis, stroke, as well as neurological and cognitive impairments [8]. Besides, obese patients are at higher risk of death than non-obese individuals. Obesity is a major driver for disability, early retirement, and psychological disorders as well [9].

Clinically, obesity is recognized as a Body Mass Index (BMI) of more than $30 \mathrm{Kg} / \mathrm{m}^{2}$ [4] . BMI is widely utilized clinical measure as a marker of percentage fat mass for defying and classifying obesity, previous reports showed that BMI is simple and reliable tool for assessment and follow-up of obese individuals [10]. Nonetheless, BMI, as well other anthropometric measures such Waist Circumference (WC), suffers for many limitations; firstly, the BMI-based obesity definition is based on statistical cut-off values without consideration of the age and ethnicity [11]. Besides, the BMI does not take into account the presence and impact of comorbidities on affected patients [10]. Thus, continuous efforts were devoted to develop direct measures of body fat accumulation. Visceral adipose tissue has emerged as an active, reliable, surrogate for body fat accumulation; through its distinct biochemical features, the visceral adipose tissue demonstrated significant involvement in many pathological processes in obese patients. Over the recent years, several quantitative measures were proposed for visceral adipose tissue assessment, such as bioelectrical impedance analysis and imaging-based analysis, with variable accuracy [12] Abdominal wall fat index (AFI), firstly described bySuzuki et al. [13], in early 1990s, is a widely utilized sonographic measure for regional fat accumulation; it is calculated as a ratio of the highest to lowest preperitoneal and subcutaneous fat thicknesses, respectively [14]. Several reports demonstrated that AFI is a simple and reliable tool for regional fat assessment; besides, it was found to significantly correlated with the risk of metabolic disorders, such as dyslipidemia, cardiovascular diseases, and diabetes [15].
On the other hand, Carotid Intima Media Thickness (CIMT) is a well-established marker for early atherosclerosis, as well as other vascular abnormalities, in children and adults. Previous reported indicated higher thickness of CIMT in pediatric population with hypertension [16] and other cardiovascular diseases [17]. Moreover, the current body of evidence suggests that CIMT is significantly positively correlated with the degree of obesity and other metabolic abnormalities in children [18]

To our knowledge few reports have focused on the measurements of lipid profile and its relation with the abdominal wall fat index (AFI) and Carotid Intima Media Thickness (CIMT). In this report, we aimed to investigate the relationship between AFI and CIMT with lipid profile among obese patients.

\section{Aim of the work:}

Investigating the relationship between abdominal wall fat index (AFI) and Carotid Intima Media Thickness (CIMT) as measured by ultrasonography with lipid profile among obese patients.

\section{Patients and Methods}

We performed a cross-sectional study on participants aged 22-66 years old of both genders at Department of Radiology, Abassia Fever Hospital, Egypt from January 2020 to June 2020.

The study was conducted only after obtaining approval of Ethical Committee of Ministry of Health and written informed consent from all the participants.

\section{Study participant:}

Participants were recruited from obesity clinic if they had a BMI of more than $18 \mathrm{Kg} / \mathrm{m}^{2}$. We excluded participants with history of upper abdominal surgery to minimize errors in AFI measurements. Participants were collected by simple random method.

Eligible participants were divided into three equal groups according to the AFI: Group I included participants with an AFI value of less than 0.7; group II included participants with an AFI values of $>0.7$ to $<1.4$; and group III included participants with an AFI values of $>$ 1.4. Mean age of group I was 34.6, mean age of group II was 48.7 and mean age of group III was 53.7.

\section{Data collection:}

We collected the following data from eligible participants: Age, gender, alcohol consumption, smoking status, history of comorbidities, family 
history of obesity, anthropometric measures, lipid profile parameters, and sonographic measures of AFI and CIMT.

To measure the BMI, a trained nurse asked the participants to wear light clothes only and be barefooted. Then, the weight and height were measured according to the standards of the institution. The BMI was calculated from the following equation: Weight in $\mathrm{Kg} /(\text { height in } \mathrm{m})^{2}$

On the other hand, the B-mode ultrasound machine was used to assess the AFI and CIMT.

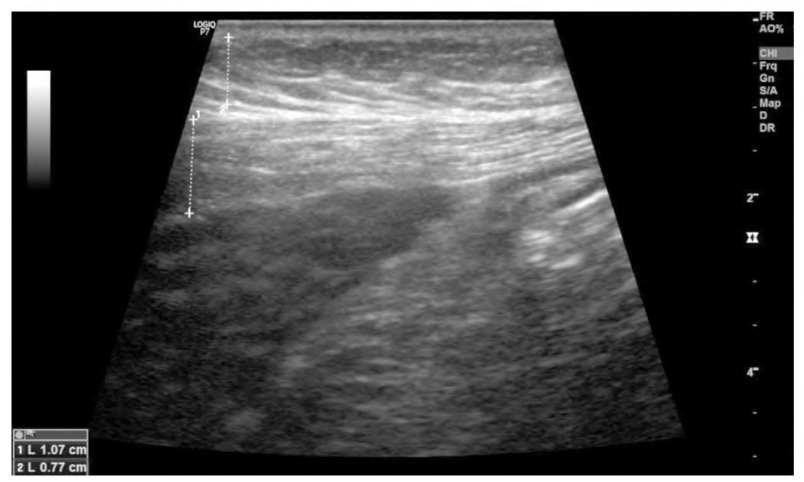

Fig. (1): Showing AFI being measured using ultrasound.

\section{Statistical analysis:}

Data were analyzed using Statistical Program for Social Science (SPSS) version 20.0. We employed descriptive analysis (mean \pm Standard Deviation [SD] and frequency for quantitative and qualitative data, respectively) to describe different parameters of the study. The independent t-test or Mann-Whitney test were used to assess the association between erectile index and different parameters.

\section{Results}

A total of 60 participants (20 participants per group) were included. The mean AFI in group I, II, and III was $0.7 \pm 0.1,1.2 \pm 0.2$, and $2 \pm 0.2$, respectively. Patients in group III had significantly higher age than group I and II (53.7 \pm 11 versus $34.6 \pm 12.9$ and $48.7 \pm 14.3$ years old, respectively; $p=0.001$ ). However, the gender distribution was similar across the three groups $(p=0.247)$. Concerning comorbidities, $50 \%$ and $45 \%$ of the group II and III suffered from both hypertension and diabetes, respectively, compared to only $5 \%$ in group I $(p=0.006)$. Besides, group III had the highest level of smoking (40\%; $p=0.001)$. There was no statistically significant difference between groups regarding alcohol consumption $[p=0.221$; Table (1)].
For AFI, participants were instructed to lay on supine position; while $12-\mathrm{MHz}$ linear transducer probe was placed at 90 degrees vertically on the epigastrium. Then, the examination was continued from the xiphoid process to the umbilicus. The ratio between the maximum thickness of preperitoneal fat (Pmax) at the anterior surface of the liver to the minimum of the subcutaneous fat (Smin) of the abdomen was calculated. Concerning the CIMT measurement, the distance between the media-adventitia interface and the lumen-intima interface is measured.

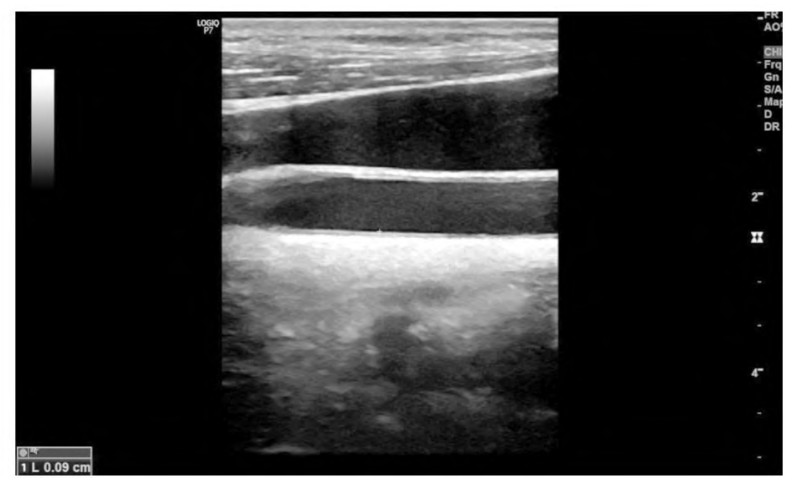

Fig. (2): Showing the CIMT being measured using ultrasound.

Regarding the association between AFI and BMI, participants in group III had significantly higher BMI value $\left(34.1 \pm 5.8 \mathrm{Kg} / \mathrm{m}^{2}\right)$ than group I $\left(25 \pm 2.2 \mathrm{Kg} / \mathrm{m}^{2}\right)$ and group II $\left(30.3 \pm 4 \mathrm{Kg} / \mathrm{m}^{2} ; p=\right.$ $0.001)$. Besides, patients in group II significantly higher BMI value than group I Fig. (3). As expected, there was a positive correlation between the AFI and all lipid profile parameters; participants in group III had significantly higher total cholesterol $(p=0.001)$, low-density lipoprotein $(p=0.001)$, triglyceride $(p=0.001)$, and lower high-density lipoprotein $(p=0.001)$ than group I and II (Table 2$)$.

With regard to the primary outcome of the present study, we found that the group III had the highest level of CIMT $(1.4 \pm 0.3 \mathrm{~mm})$, followed by group II $(1.2 \pm 0.3 \mathrm{~mm})$, and finally group I [0.7 \pm $0.3 \mathrm{~mm} ; p=0.001 ;$ Table (3)]. Table (4) shows the correlation between the CIMT, lipid profile, BMI, and AFI. There was a statistically significant positive strong correlation with total cholesterol ( $r=$ $0.849, p=0.001)$, low-density lipoprotein $(r=0.815$, $p=0.001)$, and triglycerides $(r=0613, p=0.001)$. Besides, there was a statistically significant negative strong correlation between CIMT and high-density lipoprotein $(r=-0.815, p=0.001)$. There was a statistically significant positive strong correlation between CIMT and BMI ( $r=0.544, p=0.001)$. No- 
tably, there was a statistically significant positive strong correlation between CIMT with AFI ( $r=$ $0.747, p=0.001)$. Regarding the correlations be- tween AFI and lipid profile, there was a statistically significant positive correlation between AFI and lipid profile parameters.

Table (1): Characteristics of the studied groups.

\begin{tabular}{|c|c|c|c|c|c|c|c|c|}
\hline \multirow[t]{2}{*}{ Characteristics } & \multicolumn{2}{|c|}{$\begin{array}{l}\text { Group I } \\
(\mathrm{n}=20)\end{array}$} & \multicolumn{2}{|c|}{$\begin{array}{l}\text { Group II } \\
(\mathrm{n}=20)\end{array}$} & \multicolumn{2}{|c|}{$\begin{array}{l}\text { Group III } \\
(\mathrm{n}=20)\end{array}$} & \multirow[t]{2}{*}{$x^{2}$} & \multirow[t]{2}{*}{$p$} \\
\hline & \multirow{2}{*}{\multicolumn{2}{|c|}{$34.6 \pm 12.9$}} & & & & & & \\
\hline Mean \pm SD & & & \multicolumn{2}{|c|}{$48.7 \pm 14.3$} & \multicolumn{2}{|c|}{$53.7 \pm 11$} & 12.008 & $0.001 *$ \\
\hline Range & \multicolumn{2}{|c|}{$22-59$} & \multicolumn{2}{|c|}{$28-70$} & \multicolumn{2}{|c|}{$30-66$} & & \\
\hline \multicolumn{9}{|l|}{ Gender: } \\
\hline Female & 9 & $45.0 \%$ & 13 & $65.0 \%$ & 8 & $40.0 \%$ & 2.800 & 0.247 \\
\hline Male & 11 & $55.0 \%$ & 7 & $35.0 \%$ & 12 & $60.0 \%$ & & \\
\hline \multicolumn{9}{|l|}{ Medical history: } \\
\hline No hypertension nor diabetes & 19 & $95.0 \%$ & 10 & $50.0 \%$ & 7 & $35.0 \%$ & 18.200 & $0.006^{*}$ \\
\hline Hypertension & 0 & $0.0 \%$ & 2 & $10.0 \%$ & 3 & $15.0 \%$ & & \\
\hline Diabetes & 1 & $5.0 \%$ & 2 & $10.0 \%$ & 1 & $5.0 \%$ & & \\
\hline Both & 0 & $0.0 \%$ & 6 & $30.0 \%$ & 9 & $45.0 \%$ & & \\
\hline \multicolumn{9}{|l|}{ Smoking status: } \\
\hline Non-smoker & 20 & $100.0 \%$ & 20 & $100.0 \%$ & 12 & $60.0 \%$ & 18.462 & $0.001 *$ \\
\hline Smoker & 0 & $0.0 \%$ & 0 & $0.0 \%$ & 8 & $40.0 \%$ & & \\
\hline
\end{tabular}

Table (2): Difference in lipid profile parameters according to the studied groups.

\begin{tabular}{|c|c|c|c|c|}
\hline \multirow{2}{*}{ Group } & \multicolumn{2}{|c|}{ Lipid profile } & \multirow{2}{*}{$\mathrm{F}$} & \multirow{2}{*}{$p$} \\
\hline & Mean \pm SD & Range & & \\
\hline \multicolumn{5}{|c|}{ Total cholesterol (TC): } \\
\hline Group I & $171.3 \pm 21.8$ & $147.0-233.0$ & 19.031 & $0.001 *$ \\
\hline Group II & $204.6 \pm 26.9$ & $165.0-240.0$ & & \\
\hline Group III & $214.1 \pm 19.9$ & $165.0-230.0$ & & \\
\hline \multicolumn{5}{|c|}{ Low density lipoprotein: } \\
\hline Group I & $91.9 \pm 18.7$ & $80.0-140.0$ & 25.256 & $0.001 *$ \\
\hline Group II & $120.8 \pm 23.5$ & $82.0-155.0$ & & \\
\hline Group III & $144.4 \pm 27.2$ & $83.0-178.0$ & & \\
\hline \multicolumn{5}{|c|}{ High density lipoprotein: } \\
\hline Group I & $51.2 \pm 6.7$ & $38.0-68.0$ & 14.752 & $0.001 *$ \\
\hline Group II & $42.2 \pm 6.6$ & $33.0-52.0$ & & \\
\hline Group III & $40.2 \pm 7.1$ & $35.0-55.0$ & & \\
\hline \multicolumn{5}{|c|}{ Triglycerides: } \\
\hline Group I & $96.3 \pm 25.6$ & $40.0-160.0$ & 14.689 & $0.001 *$ \\
\hline Group II & $124.1 \pm 48.0$ & $33.0-185.0$ & & \\
\hline Group III & $156.9 \pm 28.4$ & $88.0-177.0$ & & \\
\hline
\end{tabular}

F: One way Analysis of Variance (ANOVA).

*: Statistically significant. 
Table (3): The difference in CIMT according to the studied groups.

\begin{tabular}{|c|c|c|c|c|}
\hline \multirow[t]{2}{*}{ Group } & \multicolumn{2}{|c|}{$\begin{array}{l}\text { Carotid intima } \\
\text { media thickness }\end{array}$} & \multirow[t]{2}{*}{$\mathrm{F}$} & \multirow[t]{2}{*}{$p$} \\
\hline & Mean \pm SD & Range & & \\
\hline Group I & $0.7 \pm 0.3$ & $0.5-1.4$ & 40.315 & $0.001 *$ \\
\hline Group II & $1.2 \pm 0.3$ & $0.7-1.6$ & & \\
\hline Group III & $1.4 \pm 0.3$ & $0.8-1.6$ & & \\
\hline
\end{tabular}

F: One way Analysis of Variance (ANOVA).

*: Statistically significant.

Table (4): Correlation analysis.

\begin{tabular}{|c|c|c|}
\hline Correlation & CIMT mm & AFI \\
\hline \multicolumn{3}{|c|}{ Total cholesterol (TC): } \\
\hline$r$ & 0.849 & 0.636 \\
\hline$p$ & $0.001^{*}$ & $0.001 *$ \\
\hline \multicolumn{3}{|c|}{ Low density lipoprotein: } \\
\hline$r$ & 0.815 & 0.68 \\
\hline$p$ & $0.001 *$ & $0.001 *$ \\
\hline \multicolumn{3}{|c|}{ High density lipoprotein: } \\
\hline$r$ & -0.677 & -0.597 \\
\hline$p$ & $0.001 *$ & $0.001 *$ \\
\hline \multicolumn{3}{|c|}{ Triglycerides: } \\
\hline$r$ & 0.613 & 0.6 \\
\hline$p$ & $0.001^{*}$ & $0.001 *$ \\
\hline \multicolumn{3}{|c|}{ Body mass index (BMI): } \\
\hline$r$ & 0.544 & \\
\hline$p$ & $0.001^{*}$ & \\
\hline \multicolumn{3}{|l|}{ AFI: } \\
\hline$r$ & 0.747 & \\
\hline$p$ & $0.001 *$ & \\
\hline
\end{tabular}

BMI

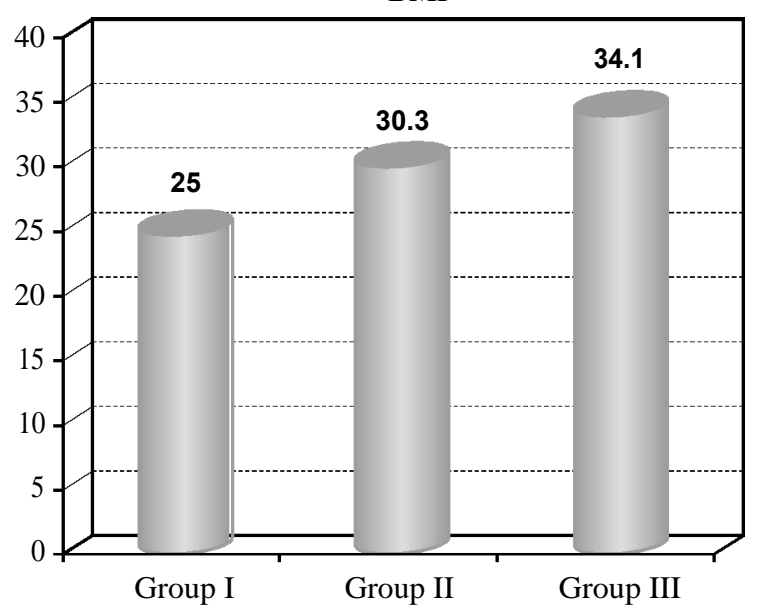

Fig. (1): BMI.

\section{Discussion}

In this report, we provide an insight about the role of AFI in assessing visceral obesity, as well as its correlation with the extent of carotid atherosclerosis as measured by CIMT. We found that the AFI significantly correlated with BMI and lipid profile parameters, confirming its role as a surrogate for obesity and excessive fat accumulation. The AFI also tended to be higher with participants suffering with both hypertension and diabetes, as well as smokers. Notably, we found that the AFI positively correlated with the degree of carotid atherosclerosis, as measured by CIMT. Patients with high increase in AFI demonstrated higher CIMT values than patients with normal or moderate increase in the AFI; likewise, patients with moderate increase in the AFI had higher CIMT than patients with normal AFI.

Although BMI is universally utilized as an indicator of obesity, the use of BMI solely to assess obese patients had many disadvantages concerning its reliability to reflect body compositions, especially visceral fat deposit [19]. On the other hand, the use of Dual-Energy X-ray Absorptiometry (DEXA) in the setting of obesity assessment is limited by its high cost and hazards of radiation exposure, despite its reliability [20]. The lack of standardized parameters for various DEXA devices is another limitation [21]. Recently, ultrasoundbased measurements were proposed as cheap, widely-available, and simple tools for assessment of body fat, mainly abdominal-fat. These measurements have proven their validity and reducibility in monitoring abdominal fat; besides, previous reports demonstrated that ultrasound-based measurements correlated significantly with the risk of obesity-associated metabolic disorders [22]. AFIis a surrogate for regional obesity that was found to correlate with the risk of metabolic disorders, such as dyslipidemia, cardiovascular diseases, and diabetes [15]. In the present study, we found that the AFI significantly correlated with BMI, presence of comorbidities, and lipid profile parameters, confirming its role as a surrogate for obesity and excessive fat accumulation. In agreement with our findings, Kwon et al., demonstrated that higher AFI was independent predictor of higher BMI [23] Another report showed similar findings [24]. On the same line, Kotani et al., showed a significant positive correlation between AFI and diastolic blood pressure [25]. Another report on 62 patients found positive correlation between AFI and serum triglyceride levels [26]. 
As previously stated, CIMT is a well-established marker for early atherosclerosis and correlated with the risk of metabolic disorders $[\mathbf{1 6 , 1 7 ]}$. In the present study, we confirmed that the AFI positively correlated with the degree of carotid atherosclerosis, as measured by CIMT. The CIMT correlated with the preperitoneal fat thickness and AFI ratio. We also found that the CIMT tended to be higher in participants with higher BMI. Similar to our findings, a study on 297 non obese male patients showed linear association between AFI and CIMT; the AFI was a significant independent contributing factor to carotid atherosclerosis [27]. Another study conducted by previous study authors but included only women with BMI more than $22 \mathrm{~kg} / \mathrm{m}^{2}$. Multiple regression analysis yielded similar results, AFI was a predictor for carotid atherosclerosis [OR= 2.995; 95\% CI, 1.106-8.109] [28]. Likewise, Cetin et al., showed that AFI was correlated with CIMT [29]. On contrary, in Jung et al., the AFI was not correlated with CIMT in either men or women. It worth notice that all study participants had type 2 diabetes mellitus [30]. On the other hand, a crosssectional study showed that visceral fat thickness, not subcutaneous fat thickness, was associated with carotid atherosclerosis [31].

Our result was consistent with previous studies but used different indicators for visceral obesity other than AFI. For example, Oike et al., showed that abdominal visceral fat area was independently associated with CIMT changes [32]. Likewise, Tripathy et al., showed that visceral fat was the strongest independent predictor of CIMT [33] Kawamoto et al., also found that the interaction between BMI and visceral obesity was significantly associated with CIMT [34]. All mentioned studies focused on visceral fat alone accumulation, Bouchi et al., investigated the risk of high visceral fat accumulation with low subcutaneous fat on progression of atherosclerosis. Results showed high visceral fat accumulation with low subcutaneous fat was as important determinant of carotid atherosclerosis. Furthermore high subcutaneous fat could be protective against atherosclerosis [36] .

The main limitation of this study, it was an observational, non-randomized cohort of patients. Results of the current study reflects the situations of a single-center which may hinder the generalizations of the results on all populations. We did not follow-up the included patients for long duration. Also, only 60 patients met our inclusion criteria. However, this is still, to the best of our knowledge, our study provided further insight in the associated between visceral fat and carotid atherosclerosis.

\section{Conclusion:}

AFI has a significant correlation with carotid intima media thickness along with preperitoneal fat thickness. Furthermore, low subcutaneous fat might have a protective effect on carotid atherosclerosis progression.

AFI is a significant independent contributing factor along with known risk factors such as age, systolic blood pressure, total-cholesterol, and HDLcholesterol. AFI can be useful in evaluating disorders of metabolism, circulation and atherosclerosis.

\section{References}

1- KYLE T.K., DHURANDHAR E.J. and ALLISON D.B.: Regarding Obesity as a Disease: Evolving Policies and Their Implications. Endocrinology and Metabolism Clinics of North America, 45 (3): 511-20, 2016.

2- McGUIRE S.: U.S. Department of Agriculture and U.S. Department of Health and Human Services, Dietary guidelines for Americans, 2010. 7 th edition, Washington, DC: U.S. Government printing office, January 2011. Adv. Nutr., 2 (3): 293-4, 2011.

3- Di CESARE M., BENTHAM J., STEVENS G.A., ZHOU B., DANAEI G., LU Y., et al.: Trends in adult body-mass index in 200 countries from 1975 to 2014: A pooled analysis of 1698 population-based measurement studies with 19.2 million participants. Lancet, 387 (10026): 1377 96, 2016.

4- BLÜHER M.: Obesity: Global epidemiology and pathogenesis. Nature Reviews Endocrinology, 15 (5): 288-98, 2019.

5- Obesity and overweight. https://www.who.int/news-room/ fact-sheets/detail/obesity-and-overweight. Accessed 30 November 2020.

6- KAILA B. and RAMAN M.: Obesity: A review of pathogenesis and management strategies. Canadian Journal of Gastroenterology, 22 (1): 61-8, 2008.

7- KARAGEORGI S., ALSMADI O. and BEHBEHANI K.: A review of adult obesity prevalence, trends, risk factors, and epidemiologic methods in Kuwait. Journal of Obesity. 2013. doi:10.1155/2013/378650, 2013.

8- BRAY G.A., KIM K.K. and WILDING J.P.H.: Obesity: A chronic relapsing progressive disease process. A position statement of the World Obesity Federation. Obes. Rev., 18 (7): 715-723, 2017.

9- FONTAINE K.R., REDDEN D.T., WANG C., WESTFALL A.O. and ALLISON D.B.: Years of life lost due to obesity. J. Am. Med. Assoc., 289 (2): 187-93, 2003.

10- PRENTICE A.M. and JEBB S.A.: Beyond body mass index. Obesity Reviews, 2 (3): 141-7, 2001.

11- MÜLLER M.J. and GEISLER C.: Defining obesity as a disease. European Journal of Clinical Nutrition, 71 (11): 1256-8, 2017.

12- SHUSTER A., PATLAS M., PINTHUS J.H. and MOURTZAKIS M.: The clinical importance of visceral adiposity: A critical review of methods for visceral adipose tissue analysis. British Journal of Radiology, 85 (1009): 1-10, 2012. 
13- SUZUKI R., WATANABE S., HIRAI Y., AKIYAMA K., NISHIDE T., MATSUSHIMA Y., et al.: Abdominal wall fat index, estimated by ultrasonography, for assessment of the ratio of visceral fat to subcutaneous fat in the abdomen. Am. J. Med., 95 (3): 309-14, 1993.

14- VLACHOS I. S., HATZIIOANNOU A., PERELAS A. and PERREA D.N.: Sonographic Assessment of Regional Adiposity. Am. J. Roentgenol., 189 (6): 1545-53, 2007.

15- De MICHELE M., PANICO S., IANNUZZI A., CELENTANO E., CIARDULLO A.V., GALASSO R., et al.: Association of obesity and central fat distribution with carotid artery wall thickening in middle-aged women. Stroke, 33 (12): 2923-8, 2002.

16- BARONCINI L.A.V., SYLVESTRE L. De C., BARONCINI C.V. and FILHO R.P.: Assessment of carotid intimamedia thickness as an early marker of vascular damage in hypertensive children. Arq. Bras. Cardiol., 108 (5): 452-7, 2017.

17- JÄRVISALO M.J., JARTTI L., NÄNTÖ-SALONEN K., IRJALA K., RÖNNEMAA T., HARTIALA J.J., et al.: Increased aortic intima-media thickness: A marker of preclinical atherosclerosis in high-risk children. Circulation, 104 (24): 2943-7, 2001.

18- MEYER A.A., KUNDT G., STEINER M., SCHUFFWERNER P. and KIENAST W.: Impaired flow-mediated vasodilation, carotid artery intima-media thickening, and elevated endothelial plasma markers in obese children: The impact of cardiovascular risk factors. Pediatrics, 117 (5): 1560-7, 2006.

19- SHARPE J.K., BYRNE N.M., STEDMAN T.J. and HILLS A.P.: Bioelectric impedance is a better indicator of obesity in men with schizophrenia than body mass index. Psychiatry Res., 159 (1-2): 121-6, 2008.

20- PLANK L.D.: Dual-energy X-ray absorptiometry and body composition. Current Opinion in Clinical Nutrition and Metabolic Care, 8 (3): 305-9, 2005.

21- PINEAU J.C., LALYS L., BOCQUET M., GUIHARDCOSTA A.M., POLAK M., FRELUT M.L., et al.: Ultrasound measurement of total body fat in obese adolescents. Ann. Nutr. Metab., 56 (1): 36-44, 2010.

22- STOLK R.P., WINK O., ZELISSEN P.M.J., MEIJER R., VAN GILS A.P.G. and GROBBEE D.E.: Validity and reproducibility of ultrasonography for the measurement of intra-abdominal adipose tissue. Int. J. Obes., 25 (9): 1346-51, 2001

23- KWON S. and HAN A.L.: The Correlation between the Ratio of Visceral Fat Area to Subcutaneous Fat Area on Computed Tomography and Lipid Accumulation Product as Indexes of Cardiovascular Risk. J. Obes. Metab. Syndr., 28 (3): 186-93, 2019.

24- OH Y.H., MOON J.H., KIM H.J. and KONG M.H.: Visceral-to-subcutaneous fat ratio as a predictor of the multiple metabolic risk factors for subjects with normal waist circumference in Korea. Diabetes, Metab. Syndr. Obes. Targets. Ther., 10: 505-11, 2017.

25- KOTANI K., ADACHI S., TSUZAKI K. and SAKANE N.: Relationship between the abdominal wall fat index and blood pressure in elderly women: A comparison with the body mass index. Aging. Clin. Exp. Res., doi: 10.1007/ BF03324926, 2009.

26- SUZUKI R., WATANABE S., HIRAI Y., AKIYAMA K., NISHIDE T., MATSUSHIMA Y., et al.: Abdominal wall fat index, estimated by ultrasonography, for assessment of the ratio of visceral fat to subcutaneous fat in the abdomen. Am. J. Med. doi: 10.1016/0002-9343(93)90284$\mathrm{V}, 1993$.

27- KAWAMOTO R., OKA Y., TOMITA H., KODAMA A. and OOTSUKA N.: Association between abdominal wall fat index on ultrasonography and carotid atherosclerosis in non-obese men. J. Atheroscler. Thromb., doi:10.5551/ jat.12.85, 2005.

28- KAWAMOTO R., KAJIWARA T., OKA Y. and TAKAGI Y.: Association between abdominal wall fat index and carotid atherosclerosis in women. J. Atheroscler. Thromb., doi: 10.5551/jat.9.213, 2002.

29- ÇETIN N., TATARIG., YÜCEEGE M., ERGUN O. and HEKIMO GLU B.: Ultrasonographic evaluation of abdominal wall fat index, carotid intima-media thickness and plaque score in obstructive sleep apnea syndrome. Med. Ultrason., doi: 10.11152/mu-1949, 2019.

30- JUNG C.H., KIM B.Y., KIM K.J., JUNG S.H., KIM C.H., KANG S.K., et al.: Contribution of subcutaneous abdominal fat on ultrasonography to carotid atherosclerosis in patients with type 2 diabetes mellitus. Cardiovasc. Diabetol., doi: 10.1186/1475-2840-13-67, 2014.

31- LEE M.J., SHIN D.H., KIM S.J., OH H.J., YOO D.E., KIM J.K., et al.: Visceral fat thickness is associated with carotid atherosclerosis in peritoneal dialysis patients. Obesity, doi: 10.1038/oby.2011.245, 2012.

32- OIKE M., YOKOKAWA H., FUKUDA H., HANIU T., OKA F., HISAOKA T., et al.: Association between abdominal fat distribution and atherosclerotic changes in the carotid artery. Obes. Res. Clin. Pract., doi:10.1016/ j.orcp.2013.09.002, 2014.

33- TRIPATHY P., SAHU A., SAHU M. and NAGY A.: Ultrasonographic evaluation of intra-abdominal fat distribution and study of its influence on subclinical atherosclerosis in women with polycystic ovarian syndrome. Eur. J. Obstet. Gynecol. Reprod. Biol., doi:10.1016/ j.ejogrb.2017.08.011, 2017.

34- KAWAMOTO R., OHTSUKA N., NINOMIYA D. and NAKAMURA S.: Association of obesity and viscelar fat distribution with intima-media thickness of carotid arteries in middle-aged and older persons. Intern. Med., doi: 10.2169/internalmedicine.47.0478, 2008.

35- LIU K.H., CHAN Y.L., CHAN J.C.N. and CHAN W.B.: Association of carotid intima-media thickness with mesenteric, preperitoneal and subcutaneous fat thickness. Atherosclerosis, doi: 10.1016/j.atherosclerosis.2004. $10.038,2005$.

36- BOUCHI R., TAKEUCHI T., AKIHISA M., OHARA N., NAKANO Y., NISHITANI R., et al.: High visceral fat with low subcutaneous fat accumulation as a determinant of atherosclerosis in patients with type 2 diabetes. Cardiovasc Diabetol., doi: 10.1186/s12933-015-0302-4, 2015.

37- KIM S.K., PARK S.W., KIM S.H., CHA B.S., LEE H.C. and CHO Y.W.: Visceral fat amount is associated with carotid atherosclerosis even in type 2 diabetic men with 
a normal waist circumference. Int. J. Obes., doi: 10.1038/ ijo.2008.222, 2009.

38- KIM C.S., KIM S.K., ARANETA M.R.G., LEE E.J., BARRETT-CONNOR E. and HUH K.B.: Can increased visceral adiposity without body weight changes accelerate carotid atherosclerosis in South Korean participants with type 2 diabetes? J. Diabetes Complications, doi: 10.1016/ j.jdiacomp.2015.06.007, 2015.

39- GAST K.B., DEN HEIJER M., SMIT J.W.A., WIDYA
R.L., LAMB H.J., De ROOS A., et al.: Individual contributions of visceral fat and total body fat to subclinical atherosclerosis: The NEO study. Atherosclerosis, doi: 10.1016/j. atherosclerosis. 20 15.05.026, 2015.

40- RALLIDIS L.S., BAROUTSI K., ZOLINDAKI M., KARAGIANNI M., VAROUNIS C., DAGRES N., et al. Visceral adipose tissue is a better predictor of subclinical carotid atherosclerosis compared with waist circumference. Ultrasound Med. Biol., doi: 10. 101 6/j.ultrasmedbio.2013. 12.017, 2014.

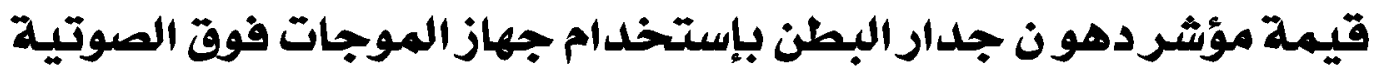

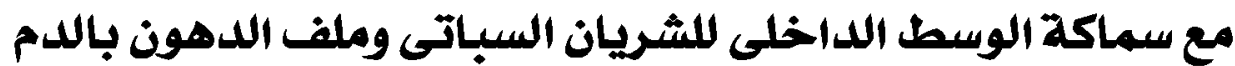

\author{
فى هذه الدراسة قمنا بدراسة العلاقة بين مؤشر دهون جدار البطن وسماكة بطانة الشريان السباتى مع ملف الدهون بالدم بين المرضى \\ الذين يعانون من زيادة الوزن والسمنة.
}

الهدف من هذه الدراسة: هو دراسة العلاقة بين مؤشر دهون جدار البطن وسمك الوسط الداخلى اللشريان السباتى كما تم قياسه بالتصوير

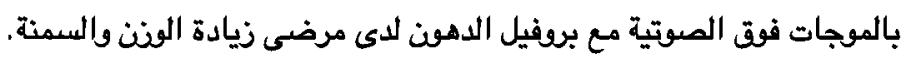

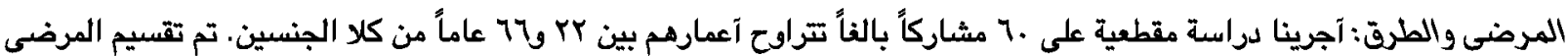

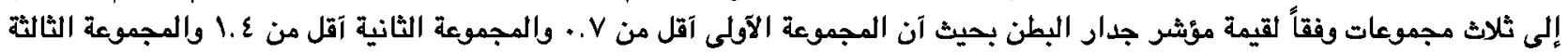

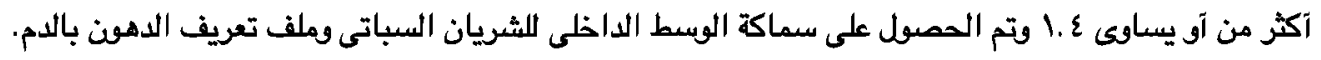

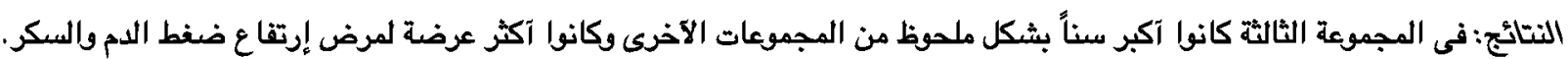

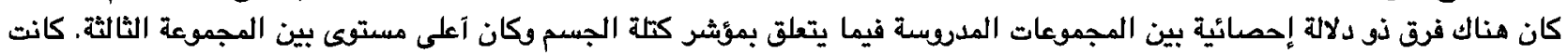

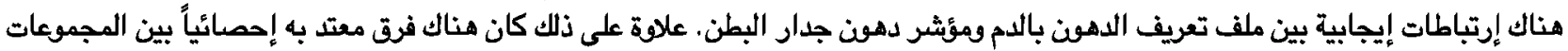

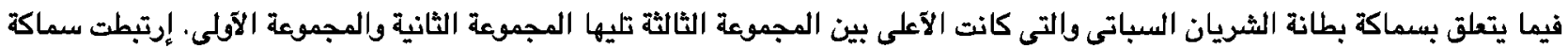

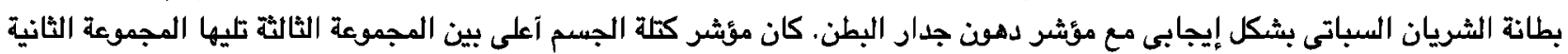

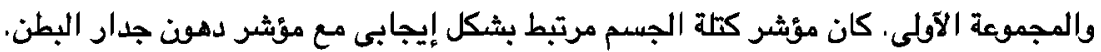

الخاتمة: مؤشر دهون جدار البطن له علاقة إيجابية مع سماكة بطانة الشريان السباتى. يمكن آن يكون مؤشر دهون جدار البطن علامة مفيدة فى تقييم والتنبؤ بإضطرابات التمثل الغذائى والدوة الدموية الدية وتصلب الشرايين. 